\title{
Article \\ Acute Effects of High Doses of Caffeine on Bar Velocity during the Bench Press Throw in Athletes Habituated to Caffeine: A Randomized, Double-Blind and Crossover Study
}

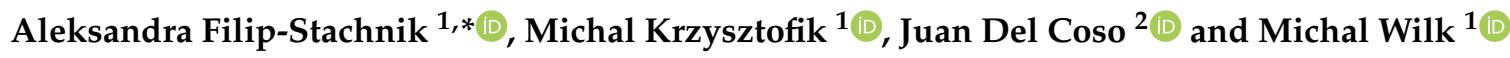 \\ 1 Institute of Sport Sciences, Jerzy Kukuczka Academy of Physical Education, 40-065 Katowice, Poland; \\ m.krzysztofik@awf.katowice.pl (M.K.); m.wilk@awf.katowice.pl (M.W.) \\ 2 Exercise Physiology Laboratory, Universidad Rey Juan Carlos, 28942 Fuenlabrada, Spain; \\ juan.delcoso@urjc.es \\ * Correspondence: a.filip@awf.katowice.pl
}

check for updates

Citation: Filip-Stachnik, A.; Krzysztofik, M.; Del Coso, J.; Wilk, M. Acute Effects of High Doses of Caffeine on Bar Velocity during the Bench Press Throw in Athletes Habituated to Caffeine: A Randomized, Double-Blind and Crossover Study. J. Clin. Med. 2021, 10, 4380. https://doi.org/10.3390/ jcm10194380

Academic Editor: Joel T. Cramer

Received: 23 August 2021

Accepted: 23 September 2021

Published: 25 September 2021

Publisher's Note: MDPI stays neutral with regard to jurisdictional claims in published maps and institutional affiliations.

Copyright: (c) 2021 by the authors. Licensee MDPI, Basel, Switzerland. This article is an open access article distributed under the terms and conditions of the Creative Commons Attribution (CC BY) license (https:// creativecommons.org/licenses/by/ $4.0 /)$.

\begin{abstract}
Chronic intake of caffeine may produce a reduction in the potential performance benefits obtained with the acute intake of this substance. For this reason, athletes habituated to caffeine often use high doses of caffeine ( $\geq 9 \mathrm{mg} / \mathrm{kg}$ ) to overcome tolerance to caffeine ergogenicity due to chronic intake. The main objective of the current investigation was to evaluate the effects of high caffeine doses on bar velocity during an explosive bench press throw in athletes habituated to caffeine. Twelve resistance-trained athletes, with a moderate-to-high chronic intake of caffeine $(\sim 5.3 \mathrm{mg} / \mathrm{kg} /$ day $)$ participated in a randomized double-blind and randomized experimental design. Each participant performed three identical experimental sessions $60 \mathrm{~min}$ after the intake of a placebo (PLAC) or after the intake of 9 (CAF-9) or $12 \mathrm{mg} / \mathrm{kg}$ (CAF-12) of caffeine. In each experimental session, the athletes performed five sets of two repetitions of the bench press throw exercise with a load equivalent to $30 \%$ of their one-repetition maximum. In comparison to PLAC, the intake of caffeine increased peak and mean velocity $(p<0.01)$ during the five sets of the bench press throw exercise. There were no significant differences in peak and mean bar velocity between the two doses of caffeine (CAF-9 vs. CAF-12; $p=0.91,=0.96$, respectively). The ingestion of high doses of caffeine was effective in producing an increase in mean and peak bar velocity during the bench press throw in a group of habitual caffeine users. However, using CAF-12 did not offer additional benefits for performance with respect to CAF-9.
\end{abstract}

Keywords: resistance exercise; upper limbs; adverse effects; ergogenic substances; sports performance

\section{Introduction}

Caffeine is the world's most consumed psychoactive drug and is widely used as a ergogenic aid in competitive sports [1]. Recently, ergogenicity of caffeine for several forms of resistance exercise (i.e., mainly muscle strength and strength-endurance) has been confirmed and summarized in several systematic reviews and meta-analyses [2-4]. There is consensus that the main mechanism explaining the ergogenic effect of caffeine for resistance exercise is the action of caffeine as an antagonist of adenosine receptors, promoting an elevated release of neurotransmitters [5]. There is also evidence based on investigations testing the effect of caffeine on isolated muscles under in vitro conditions to suggest that, under physiological concentrations of caffeine, this substance can potentiate skeletal muscle force and muscle power, which can contribute to the overall ergogenic effect of caffeine on resistance exercise [6]. Collectively, it seems that caffeine's ergogenicity is obtained through a number of mechanisms that work synergistically to promote the performance-enhancing effect obtained with the acute consumption of this substance. Nevertheless, the caffeine dose required to obtain a direct effect on the skeletal muscle is greater than that needed to block adenosine receptors [7]. 
Doses of caffeine in the range of 3 to $6 \mathrm{mg} / \mathrm{kg}$ of body mass are the most commonly used to induce acute ergogenic effect of caffeine on resistance exercise because they are effective in producing benefits in several exercise and muscle performance variables [1]. However, higher doses of caffeine are often used by some athletes with the aim of augmenting the benefits obtained from normal doses of caffeine [8,9]. From a physiological point of view, the use of high doses of caffeine is not supported by evidence, as increased doses of caffeine beyond the "normal" 3-6 mg/kg-dose fail to elicit further positive responses on performance $[8,9]$. However, chronic caffeine intake may produce tolerance to the ergogenic effect of caffeine $[10,11]$ due to the new creation of binding sites for adenosine [12]. Hence, individuals with habituation to caffeine may need doses up to their habitual caffeine intake to obtain benefits from acute caffeine intake [13]. In several previous studies, high doses of caffeine (from 9 to $13 \mathrm{mg} / \mathrm{kg}$ ) have shown a positive effect of acute caffeine intake on several forms of physical performance [14-20]. However, only three of these studies analyzed the impact of high doses of caffeine (i.e., 9 and $11 \mathrm{mg} / \mathrm{kg}$ ) on performance during resistance exercise [14-16] and showed conflicting results. In the study by Pallarés et al. [16], $9 \mathrm{mg} / \mathrm{kg}$ of caffeine improved bar velocity and power output during bench press and full squat exercises with increasing loads from $25 \%$ to $90 \%$ of the one-repetition maximum (1RM). Wilk et al. [15] also found a positive effect of 9 and $11 \mathrm{mg} / \mathrm{kg}$ of caffeine to increase 1RM in the bench press exercise, but both doses failed to enhance power output and bar velocity during a strength endurance test. It should be noted that such high doses of caffeine in these three studies [14-16] led to a high frequency of side effects typically associated with caffeine intake, which showed a dose-dependent prevalence.

With this background, the use of high doses of caffeine may be an effective supplementation protocol for some athletes with high habituation to this substance through chronic intake. There is evidence showing that some individuals can consume high doses of caffeine (up to 600-800 mg/day) without experiencing such effects as tachycardia, headache or anxiety [21]. This is because the intensity and type of physiological responses to caffeine are known to vary among individuals due to differences in pharmacokinetics, pharmacodynamics, and possible tolerance [21,22]. While such doses of caffeine seem extreme and unnecessary, in some research analyzing the impact of caffeine for habitual users, the mean daily level of caffeine consumption reached these levels [23-25]. Furthermore, urine caffeine concentration higher than $12 \mu \mathrm{g} / \mathrm{mL}$ (which is obtained after intake of $\sim 10 \mathrm{mg} / \mathrm{kg}$ of caffeine) were found in several samples of athletes tested for doping control $[8,9,26]$. These data suggest that the use of high doses of caffeine exists among athletes, while the most probable cause to explain this practice is the need to use high doses of caffeine to overcome the tolerance induced by chronic intake $[10,11,23]$. Therefore, the aim of this study was to evaluate the acute effect of 9 and $12 \mathrm{mg} / \mathrm{kg}$ of caffeine on bar velocity changes in resistance-trained athletes habituated to caffeine during a bench press throw (BPT) exercise. A second purpose of this study was to evaluate the occurrence of side effects following caffeine consumption. It was hypothesized that 9 and $12 \mathrm{mg} / \mathrm{kg}$ of caffeine would similarly improve bar velocity during the resistance exercise, but the frequency of side effects would be dose-related.

\section{Methods}

\subsection{Experimental Design}

The study used a randomized, counterbalanced, double-blind, placebo-controlled crossover design, where each athlete acted as their own control. The randomization was performed by a member of the research team who was not involved in the data collection; thus, after assignment to interventions, both athletes and researchers were blinded to the trials. Athletes performed a familiarization session that included the 1RM bench press assessment and execution of several repetitions of maximal BPT exercise on a Smith machine with a load of 30\% 1RM [27]. Three identical experimental sessions followed, with a one-week interval between sessions to allow complete recovery and ensure substance wash-out. During the three identical experimental sessions, athletes 
either ingested a placebo (PLAC) or $9 \mathrm{mg} / \mathrm{kg}$ of caffeine (CAF-9) or $12 \mathrm{mg} / \mathrm{kg}$ of caffeine (CAF-12). Caffeine and the placebo were administered orally $60 \mathrm{~min}$ before the onset of the exercise protocol [28], and at least $3 \mathrm{~h}$ after the last meal, to maintain the same time of absorption. After $60 \mathrm{~min}$ of substance intake, athletes underwent five sets with two repetitions of the BPT, while the bar was loaded with $30 \%$ of their 1RM, as measured in the pre-experimental session. Caffeine was provided in the form of capsules containing the individual dose of caffeine (Olimp Laboratories, Dębica, Poland). The manufacturer of the caffeine capsules also prepared identical placebo capsules filled out with an all-purpose flour. The study protocol was approved by the by the University Ethics Committee in accordance with the latest version of the Declaration of Helsinki. This protocol was carried out during the experimental trials performed without any deviation.

\subsection{Study Participants}

To calculate the sample size, a statistical software (G*Power, Dusseldorf, Germany) was used with the following parameters: analysis of variance with repeated measures and within factors comparison as the statistical test, an expected effect size (ES) for bar velocity equal to 0.25 , an alpha level at 0.05 , a statistical power at $80 \%$, correlation among repeated measures set at $r=0.85$, and three experimental conditions. The power analysis indicated that a sample of at least 10 participants was required for this study. To account for potential drop-outs, twelve healthy strength-trained male athletes (Table 1) were recruited and volunteered after completing a written consent form. The inclusion criteria were as follows: (a) free from neuromuscular and musculoskeletal disorders, (b) "resistance-trained," defined as having a minimum of two years of resistance training experience and being able to lift at least $120 \%$ of body mass in the bench press exercise, (c) chronic caffeine intake to produce at least moderate habituation to caffeine (according to previously proposed classification) [29], and (d) previous experience in pre-workout caffeine use at a dose of $6 \mathrm{mg} / \mathrm{kg}$ with a low frequency of negative side effects. Athletes were excluded if they reported (a) a positive smoking status, (b) a potential allergy to caffeine, or (c) using any medications, dietary supplements or ergogenic aids which could potentially affect the study outcomes (e.g., beta-alanine, creatine). Habitual caffeine intake was measured by using a modified version of the validated questionnaire by Bühler et al. [30] that recorded the type and amount of caffeine-containing foods and dietary supplements. Habitual caffeine intake was recorded for the 4 weeks before the start of the experiment, following previous recommendations [29].

Table 1. Participants' characteristics.

\begin{tabular}{cc}
\hline Variable [units] & $\begin{array}{c}\text { Mean } \pm \text { Standandard Deviation } \\
(\boldsymbol{n}=\mathbf{1 2})\end{array}$ \\
\hline Age (years) & $25.2 \pm 1.3$ \\
\hline Body mass $(\mathrm{kg})$ & $85.4 \pm 13.2$ \\
\hline Height $(\mathrm{cm})$ & $180.6 \pm 4.4$ \\
\hline Body Fat $(\%)$ & $12.1 \pm 3.0$ \\
\hline Resistance training experience (years) & $4.1 \pm 1.3$ \\
\hline Bench press exercise 1RM (kg) & $121.1 \pm 30.5$ \\
\hline Ratio of 1 bench press exercise to body mass $(\%)$ & $140.6 \pm 15.0$ \\
\hline Habitual caffeine intake (mg/kg/day) & $5.3 \pm 1.4$ \\
\hline Habitual caffeine intake (mg/day) & $463.3 \pm 171.3$ \\
\hline Energy intake (kcal/day) & $3341.8 \pm 568.8$ \\
\hline Protein (\% of total energy intake) & $19.5 \pm 3.9$ \\
\hline Fat (\% of total energy intake) & $28.3 \pm 2.3$ \\
\hline Carbohydrates (\% of total energy intake) & $52.3 \pm 4.0$ \\
\hline 1RM-one-repetition maximum
\end{tabular}

1RM-one-repetition maximum. 


\subsection{Standarizations}

Athletes were instructed to maintain their usual dietary patterns and training routines during the study period and refrained from strenuous exercises $24 \mathrm{~h}$ before all experimental sessions. Athletes were asked to replicate their diet every $24 \mathrm{~h}$ before testing, recorded all the food and drinks ingested before the first experimental trial and replicated this diet in the subsequent trials. The amount of calories and the proportion of macronutrients were calculated by a qualified sports nutritionist from a 24-h diet recall (Table 1). Athletes were also asked to refrain from caffeine intake $24 \mathrm{~h}$ before each trial and by the end the experimental day. Adherence to these requirements was verified via a brief questionnaire administered prior to each trial before data collection.

\subsection{Familiarization Session and One Repetition Maximum Test}

During the familiarization session, athletes arrived at the laboratory at the same time of day as in the upcoming experimental sessions (between 10:00 and 11:00 a.m.). The warm-up protocol included $5 \mathrm{~min}$ of cycling on a stationary ergometer followed by a general upper body warm-up. Next, athletes performed 15, 10, 5, and 3 repetitions of the bench press exercise using loads corresponding to $20,40,60$ and $80 \%$ of their estimated $1 \mathrm{RM}$. The participants executed a single repetition with a constant tempo of movement ( $2 \mathrm{~s}$ duration of the eccentric phase and maximum velocity in the concentric phase, with no pause in-between) on a free barbel bench press exercise. Athletes then performed single repetitions of the bench press exercise with a 5-min rest interval between successful trials. The load for each following attempt was increased by 2.5 to $10 \mathrm{~kg}$, and the process was repeated until failure. Hand placement on the barbell was individually selected ( $150 \%$ individual bi-acromial distance). Ten minutes after completing the 1RM test, after instructions regarding the correct technique of BPT, the athletes executed several repetitions of maximal BPT exercise on a Smith machine with a load of 30\% 1RM with a maximal tempo of movement [27].

\subsection{Experimental Protocol}

All experimental trials were conducted between 10:00 and 11:00 in the morning to avoid the effects of circadian rhythm on the outcomes of the investigation. After the warmup procedures, which were the same as in the familiarization trial, the athletes performed five sets of two BPT repetitions at 30\% 1RM on the Smith machine. The repetitions were performed with maximal tempo of movement, (the participants were encouraged to produce maximal velocity during both the eccentric and concentric phase of the BPT movement) with a 3-min rest interval between sets. Two spotters caught and lowered the loaded bar to ensure safety. A rotatory encoder (Tendo Power Analyzer, Tendo Sport Machines, Trencin, Slovakia) was used for instantaneous recording of bar velocity during the whole range of motion. During each BPT, peak bar velocity (peak velocity, in $\mathrm{m} / \mathrm{s}$ ); and mean bar velocity (mean velocity, in $\mathrm{m} / \mathrm{s}$ ) were registered. Mean velocity was obtained as the mean of the two repetitions, while peak velocity was obtained from the peak value of the best repetition.

\subsection{Side Effects and Assessment of Blinding}

Immediately after finishing testing, and after $24 \mathrm{~h}$ of testing, athletes were asked about their feelings associated with typical caffeine-induced side effects by using a questionnaire (nine-item measure with a yes/no response) $[15,16,31]$. Additionally, athletes reported if they were able to identify whether they ingested caffeine or placebo.

\subsection{Statistical Analysis}

Data are presented as the mean $\pm \mathrm{SD}$ for performance variables and as frequency for the prevalence of side effects. All performance variables presented a normal distribution according to the Shapiro-Wilk test. Verification of differences in peak bar velocity (peak velocity), and mean bar velocity (mean velocity) was performed using a two-way ( $3 \times 5$; 
substance $\times$ set) analysis of variance (ANOVA) with repeated measurements. In the event of a significant main effect, post hoc comparisons were conducted using the Tukey's test. Percent changes and 95\% confidence intervals were also calculated. Effect sizes (Cohen's $d$ ) were reported where appropriate and interpreted as large $(d \geq 0.80)$; moderate ( $d$ between 0.79 and 0.50); small ( $d$ between 0.49 and 0.20); and trivial $(d<0.20)$ [32]. A Fisher's Exact test in a contingency table was conducted to evaluate whether the size of dose was associated with the occurrence of side effects. The two variables were caffeine dose with three levels (placebo, CAF-9, CAF-12) and occurrence of side effects with two levels (yes and no). Moreover, a Cochran's $Q$ test with pairwise comparison was conducted to evaluate differences between doses in the occurrence of side effects. The magnitude of association between caffeine dose and the occurrence of side effects was described by Cramer's V with the following approach: low (between 0.1 and 0.3), moderate (between 0.3 and 0.5 ) and high ( $>0.5)$. The significance level was set at $p<0.05$ for all statistical analysis.

\section{Results}

\subsection{Performance}

The two-way repeated measures ANOVA indicated a significant main effect of substance for peak velocity $(\mathrm{F}=9.12 ; p<0.01)$ and for mean velocity $(\mathrm{F}=8.79 ; p<0.01)$. Post hoc analyses for main effect of substance indicated significant increases in peak velocity after the intake of CAF-9 $(p<0.01$; ES $=0.36)$ and CAF-12 $(p<0.01$; ES $=0.33)$ compared to PLAC (Table 2). The intake of CAF-9 $(p<0.01 ; \mathrm{ES}=0.42)$ and CAF-12 $(p<0.01 ; \mathrm{ES}=0.42)$ also increased mean velocity compared to PLAC. There were no significant differences in peak velocity $(p=0.91)$ and mean velocity $(p=0.96)$ between the two doses of caffeine. The two-way repeated measures ANOVA indicated no significant substance $\times$ set main interaction effect for peak velocity $(\mathrm{F}=0.56 ; p=0.81)$ and mean velocity $(\mathrm{F}=0.72 ; p=0.67)$. The results of mean velocity and peak velocity in individual sets for PLAC, CAF-9 and CAF-12 conditions are presented in Table 3.

Table 2. Average values of peak and mean bar velocity during five sets of the bench press throw with the ingestion of 9 and $12 \mathrm{mg} / \mathrm{kg}$ of caffeine or with a placebo in resistance trained athletes habituated to caffeine.

\begin{tabular}{ccccc}
\hline \multirow{2}{*}{ Bench Press Throw } & \multicolumn{3}{c}{ Conditions } & \multirow{2}{*}{$\boldsymbol{p}$ for Main Effect of Substance } \\
\cline { 2 - 4 } & PLAC & CAF-9 & CAF-12 & $<0.01$ \\
\hline Peak bar velocity $[\mathrm{m} / \mathrm{s}]$ & $2.17 \pm 0.19$ & $2.24 \pm 0.20$ & $2.23 \pm 0.17$ & $<0.01$ \\
\hline Mean bar velocity $[\mathrm{m} / \mathrm{s}]$ & $1.37 \pm 0.10$ & $1.41 \pm 0.09$ & $1.41 \pm 0.09$ & \\
\hline
\end{tabular}

Data represents mean values of the five sets. All data are presented as mean \pm standard deviation. PLAC: placebo; CAF-9: caffeine $9 \mathrm{mg} / \mathrm{kg}$; CAF-12: caffeine $12 \mathrm{mg} / \mathrm{kg}$.

\subsection{Side Effects and Assessment of Blinding}

In the assessment of the prevalence of side effects immediately after the end of testing, the Fisher's Exact Test showed a statistically significant association between the caffeine dose and anxiety or nervousness ( $p=0.001$; Cramer's $\mathrm{V}=0.617)$ and moderate association of dose with headache $(p=0.032$; Cramer's V $=0.455)$, increased vigor/activeness $(p=0.028$; Cramer's V $=0.478)$, and perception of performance improvement ( $p=0.075$; Cramer's $\mathrm{V}=0.403)$. Twenty-four hours after testing, statistically significant associations between caffeine dose and tachycardia and heart palpitations $(p<0.001$; Cramer's V $=0.764)$, anxiety or nervousness ( $p=0.001$; Cramer's V $=0.575)$, headache $(p<0.001$; Cramer's V $=0.727)$, increased vigor/activeness ( $p=0.006$; Cramer's V $=0.533$, and insomnia $(p=0.009$; Cramer's $\mathrm{V}=0.519$ ), were observed. Table 4 shows details of the differences determined by Cochran's $Q$ test and percentage frequency of the side effects in all three experimental trials, as assessed immediately after, and for $24 \mathrm{~h}$ after, the test protocol. 
Table 3. Peak and mean var velocity for each of the five sets of the bench press throw with the ingestion of 9 and $12 \mathrm{mg} / \mathrm{kg}$ of caffeine or with a placebo in resistance trained athletes habituated to caffeine.

\begin{tabular}{|c|c|c|c|c|c|c|}
\hline & Conditions & Set 1 & Set 2 & Set 3 & Set 4 & Set 5 \\
\hline \multicolumn{7}{|c|}{ Peak Bar Velocity [m/s] } \\
\hline & $\begin{array}{c}\text { PLAC } \\
(95 \% C I)\end{array}$ & $\begin{array}{c}2.14 \pm 0.16 \\
(2.04 \text { to } 2.25)\end{array}$ & $\begin{array}{c}2.17 \pm 0.19 \\
(2.04 \text { to } 2.29)\end{array}$ & $\begin{array}{c}2.20 \pm 0.19 \\
(2.08 \text { to } 2.33)\end{array}$ & $\begin{array}{c}2.18 \pm 0.20 \\
(2.05 \text { to } 2.31)\end{array}$ & $\begin{array}{c}2.16 \pm 0.22 \\
(2.02 \text { to } 2.31)\end{array}$ \\
\hline & $\begin{array}{l}\text { CAF-9 } \\
(95 \% \mathrm{CI})\end{array}$ & $\begin{array}{c}2.21 \pm 0.21 \\
(2.07 \text { to } 2.35)\end{array}$ & $\begin{array}{c}2.22 \pm 0.19 \\
(2.09 \text { to } 2.34)\end{array}$ & $\begin{array}{c}2.26 \pm 0.19 \\
(2.13 \text { to } 2.38)\end{array}$ & $\begin{array}{c}2.24 \pm 0.18 \\
(2.13 \text { to } 2.36)\end{array}$ & $\begin{array}{c}2.28 \pm 0.22 \\
(2.13 \text { to } 2.43)\end{array}$ \\
\hline & $\begin{array}{l}\text { CAF-12 } \\
(95 \% \mathrm{CI})\end{array}$ & $\begin{array}{c}2.20 \pm 0.14 \\
(2.10 \text { to } 2.29)\end{array}$ & $\begin{array}{c}2.23 \pm 0.17 \\
(2.11 \text { to } 2.34)\end{array}$ & $\begin{array}{c}2.24 \pm 0.17 \\
(2.13 \text { to } 2.35)\end{array}$ & $\begin{array}{c}2.24 \pm 0.18 \\
(2.12 \text { to } 2.36)\end{array}$ & $\begin{array}{c}2.26 \pm 0.19 \\
(2.13 \text { to } 2.39)\end{array}$ \\
\hline \multirow{3}{*}{ ES } & PLAC vs. CAF-9 & $\begin{array}{c}0.37 \\
(-0.44,1.17)\end{array}$ & $\begin{array}{c}0.26 \\
(-0.55,1.06)\end{array}$ & $\begin{array}{c}0.32 \\
(-0.50,1.11)\end{array}$ & $\begin{array}{c}0.32 \\
(-0.50,1.11)\end{array}$ & $\begin{array}{c}0.55 \\
(-0.29,1.34)\end{array}$ \\
\hline & PLAC vs. CAF-12 & $\begin{array}{c}0.40 \\
(-0.42,1.19)\end{array}$ & $\begin{array}{c}0.33 \\
(-0.48,1.13)\end{array}$ & $\begin{array}{c}0.22 \\
(-0.59,1.02)\end{array}$ & $\begin{array}{c}0.32 \\
(-0.59,1.01)\end{array}$ & $\begin{array}{c}0.49 \\
(-0.90,0.70)\end{array}$ \\
\hline & CAF-9 vs. CAF-12 & $\begin{array}{c}0.06 \\
(-0.85,0.75)\end{array}$ & $\begin{array}{c}0.06 \\
(-0.75,0.85)\end{array}$ & $\begin{array}{c}0.01 \\
(-0.91,0.69)\end{array}$ & $\begin{array}{c}0.00 \\
(-0.80,0.80)\end{array}$ & $\begin{array}{c}0.01 \\
(-0.89,0.71)\end{array}$ \\
\hline \multicolumn{7}{|c|}{ Mean bar velocity $[\mathrm{m} / \mathrm{s}]$} \\
\hline & $\begin{array}{c}\text { PLAC } \\
(95 \% C I)\end{array}$ & $\begin{array}{c}1.34 \pm 0.07 \\
(1.29 \text { to } 1.39)\end{array}$ & $\begin{array}{c}1.37 \pm 0.12 \\
(1.30 \text { to } 1.45)\end{array}$ & $\begin{array}{c}1.38 \pm 0.09 \\
(1.32 \text { to } 1.44)\end{array}$ & $\begin{array}{c}1.38 \pm 0.10 \\
(1.31 \text { to } 1.45)\end{array}$ & $\begin{array}{c}1.36 \pm 0.11 \\
(1.28 \text { to } 1.44)\end{array}$ \\
\hline & $\begin{array}{c}\text { CAF-9 } \\
(95 \% \mathrm{CI})\end{array}$ & $\begin{array}{c}1.42 \pm 0.12 \\
(1.34 \text { to } 1.50)\end{array}$ & $\begin{array}{c}1.40 \pm 0.07 \\
(1.36 \text { to } 1.45)\end{array}$ & $\begin{array}{c}1.40 \pm 0.10 \\
(1.34 \text { to } 1.47)\end{array}$ & $\begin{array}{c}1.43 \pm 0.08 \\
(1.38 \text { to } 1.48)\end{array}$ & $\begin{array}{c}1.42 \pm 0.08 \\
(1.36 \text { to } 1.47)\end{array}$ \\
\hline & $\begin{array}{l}\text { CAF-12 } \\
(95 \% \mathrm{CI})\end{array}$ & $\begin{array}{c}1.39 \pm 0.09 \\
(1.33 \text { to } 1.44)\end{array}$ & $\begin{array}{c}1.41 \pm 0.06 \\
(1.37 \text { to } 1.45)\end{array}$ & $\begin{array}{c}1.42 \pm 0.08 \\
(1.36 \text { to } 1.47)\end{array}$ & $\begin{array}{c}1.42 \pm 0.10 \\
(1.35 \text { to } 1.49)\end{array}$ & $\begin{array}{c}1.41 \pm 0.09 \\
(1.35 \text { to } 1.47)\end{array}$ \\
\hline \multirow{3}{*}{ ES } & PLAC vs. CAF-9 & $\begin{array}{c}0.81 \\
(-0.04,1.62) \\
\end{array}$ & $\begin{array}{c}0.31 \\
(-0.51,1.10) \\
\end{array}$ & $\begin{array}{c}0.21 \\
(-0.60,1.01) \\
\end{array}$ & $\begin{array}{c}0.55 \\
(-0.28,1.35) \\
\end{array}$ & $\begin{array}{c}0.62 \\
(-0.22,1.42) \\
\end{array}$ \\
\hline & PLAC vs. CAF-12 & $\begin{array}{c}0.62 \\
(-0.22,1.42)\end{array}$ & $\begin{array}{c}0.42 \\
(-0.40,1.22)\end{array}$ & $\begin{array}{c}0.47 \\
(-0.36,1.26)\end{array}$ & $\begin{array}{c}0.40 \\
(-0.42,1.19)\end{array}$ & $\begin{array}{c}0.50 \\
(-0.33,1.29)\end{array}$ \\
\hline & CAF-9 vs. CAF-12 & $\begin{array}{c}0.28 \\
(-1.08,0.53)\end{array}$ & $\begin{array}{c}0.15 \\
(-0.65,0.95)\end{array}$ & $\begin{array}{c}0.22 \\
(-0.59,1.02)\end{array}$ & $\begin{array}{c}0.11 \\
(-0.91,0.69)\end{array}$ & $\begin{array}{c}0.12 \\
(-0.91,0.69)\end{array}$ \\
\hline
\end{tabular}

All data are presented as mean \pm standard deviation. CI: confidence interval. PLAC: placebo; CAF-9: caffeine 9 mg/kg; CAF-12: caffeine $12 \mathrm{mg} / \mathrm{kg}$. ES: effect size.

Table 4. Frequency of side effects immediately after, and $24 \mathrm{~h}$ after, a bench press throw session with the ingestion of 9 and $12 \mathrm{mg} / \mathrm{kg}$ of caffeine or with a placebo in resistance trained athletes habituated to caffeine.

\begin{tabular}{|c|c|c|c|c|c|c|}
\hline & \multicolumn{2}{|c|}{ PLAC } & \multicolumn{2}{|c|}{ CAF-9 } & \multicolumn{2}{|c|}{ CAF-12 } \\
\hline & Just after & $24 \mathrm{~h}$ after & Just after & $24 \mathrm{~h}$ after & Just after & $24 \mathrm{~h}$ after \\
\hline Increased urine output & $8 \%$ & $0 \%$ & $25 \%$ & $33 \%$ * & $25 \%$ & $25 \%$ \\
\hline Tachycardia and heart palpitations & $17 \%$ & $0 \%$ & $33 \%$ & $17 \%$ & $67 \%+$ & $83 \%$ †\# \\
\hline Anxiety or nervousness & $6 \%$ & $0 \%$ & $42 \%$ & $33 \%$ & $83 \%+$ & $67 \%+$ \\
\hline Headache & $17 \%$ & $0 \%$ & $25 \%$ & $25 \%$ & $67 \%$ †\# & $83 \%$ †\# \\
\hline Gastrointestinal problems & $0 \%$ & $0 \%$ & $17 \%$ & $25 \%$ & $33 \%+$ & $25 \%$ \\
\hline Increased sweating & $8 \%$ & $0 \%$ & $33 \%$ & $25 \%$ & $33 \%$ & $25 \%$ \\
\hline Increased vigor/activeness & $25 \%$ & $0 \%$ & $75 \% *$ & $25 \%$ & $75 \%+$ & $58 \%+$ \\
\hline Perception of performance improvement & $25 \%$ & - & $67 \% *$ & - & $25 \% \#$ & - \\
\hline Insomnia & - & $0 \%$ & - & $33 \%$ & - & $58 \%+$ \\
\hline
\end{tabular}

Data are presented as the frequency of affirmative responses to the existence of side effects. * Significant difference $(p<0.05)$ between CAF-9 and PLAC. † Significant difference $(p<0.05)$ between CAF-12 and PLAC. \# Significant difference $(p<0.05)$ between CAF-9 and CAF-12. 
Only $33 \%$ of the sample reported that they ingested caffeine when they were given the placebo, while the remaining $92 \%$ and $100 \%$ correctly guessed caffeine trials after intake CAF-9 and CAF-12, respectively.

\section{Discussion}

The main finding of the study was that the acute intake of high doses of caffeine (i.e., 9 and $12 \mathrm{mg} / \mathrm{kg}$ ) enhanced mean and peak bar velocity during a testing protocol that included five sets of two repetitions of the BPT exercise in athletes habituated to chronic caffeine intake. Specifically, the observed ergogenic benefits were present for mean and peak velocity and for both doses of caffeine when compared to a placebo situation, while the performance benefits were of similar magnitude between caffeine doses. However, the frequency of side effects occurring immediately after the experimental trials, and during the following $24 \mathrm{~h}$, was significantly higher after the intake of CAF-12, while CAF-9 produced minimal side-effects. Therefore, the outcomes of this investigation indicate that high doses of caffeine (from 9 to $12 \mathrm{mg} / \mathrm{kg}$ ) are effective in increasing mean and peak velocity during the BPT in athletes habituated to caffeine. However, the selection of $9 \mathrm{mg} / \mathrm{kg}$ is recommended for athletes habituated to caffeine because this dosage produced an ergogenic effect on this type of resistance exercise as high as the $12 \mathrm{mg} / \mathrm{kg}$ dose but with minimal prevalence of side effects.

Previous research has shown that acute caffeine intake, of doses ranging from 3 to $9 \mathrm{mg} / \mathrm{kg}$, increases strength-power performance during different forms of resistance exercise $[16,27,33-36]$, which is in line with the results of this study. Additionally, a previous study confirmed the beneficial impact of $11 \mathrm{mg} / \mathrm{kg}$ of caffeine on maximum strength performance [15]. However, to the best of our knowledge, this is the first investigation that considered the acute impact of $12 \mathrm{mg} / \mathrm{kg}$ of caffeine during resistance exercise. The study of high doses of caffeine may be important for athletes habituated to caffeine because evidence points toward the use of high amounts of caffeine in some athletes to overcome tolerance to the ergogenic effect of caffeine developed by chronic intake. For this reason, investigations with high doses of caffeine on resistance exercise have used athletes with prior habituation to caffeine. The results of the presented study showed that both doses of caffeine (9 and $12 \mathrm{mg} / \mathrm{kg}$ ) significantly increased bar velocity during the BPT compared to the PLAC condition in athletes habituated to caffeine. Interestingly, the overall increase in bar velocity, when compared to PLAC, was of similar magnitude with the intake of 9 and $12 \mathrm{mg} / \mathrm{kg}$ of caffeine with no differences between the doses. Therefore, increasing the acute intake of caffeine to $12 \mathrm{mg} / \mathrm{kg}$ did not result in an additional enhancement of physical performance compared to $9 \mathrm{mg} / \mathrm{kg}$. A previous study by Wilk et al. [15] also showed a significant improvement of strength performance (1RM bench press test) after the intake of 9 and $11 \mathrm{mg} / \mathrm{kg}$ of caffeine, with no differences between the doses. Collectively, these data suggest that there are no additional acute benefits of consuming caffeine above a dose of $9 \mathrm{mg} / \mathrm{kg}$ in athletes habituated to caffeine, which suggests the existence of possible limits for maximum caffeine intake in habituated participants.

A previous study used an experimental protocol that included the same protocol of exercise (BPT exercise; 30\% 1 RM; five sets of two reps), resistance trained athletes habituated to caffeine and two doses of caffeine (3 and $6 \mathrm{mg} / \mathrm{kg}$ ) [27]. In that investigation, the ingestion of either 3 and $6 \mathrm{mg} / \mathrm{kg}$ of caffeine was effective in enhancing mean bar velocity, while the magnitude of the ergogenic effect was very similar to the one reported here with 9 and $12 \mathrm{mg} / \mathrm{kg}$ of caffeine [27]. However, in the prior investigation, 3 and $6 \mathrm{mg} / \mathrm{kg}$ of caffeine were ineffective in enhancing peak bar velocity, contrary to the benefits obtained with 9 and $12 \mathrm{mg} / \mathrm{kg}$. Therefore, it may be assumed that for resistance training exercise with the intention of enhancing maximal power output, it may be necessary to consume at least $9 \mathrm{mg} / \mathrm{kg}$ of caffeine in athletes habituated to caffeine.

Previous research has suggested that overall increase of performance after acute caffeine intake is associated with the participant's level of habituation to caffeine [22]. It should be noted that in the presented research the overall increase in peak and mean velocity 
occurred after the intake of 9 and $12 \mathrm{mg} / \mathrm{kg}$ of caffeine for moderate-to-high caffeine users $(5.3 \pm 1.4 \mathrm{mg} / \mathrm{kg} /$ day). Although several previous studies found positive acute effects of 3 -to- $6 \mathrm{mg} / \mathrm{kg}$ of caffeine in habituated participants [37,38], the investigations were carried out on low to mild caffeine consumers. For example, Grgic and Mikulic [38] found an increase in mean and peak velocity during the bench press exercise after the intake of $3 \mathrm{mg} / \mathrm{kg}$ of caffeine in a group consuming $235 \pm 82 \mathrm{mg} /$ day $(\sim 2.8 \mathrm{mg} / \mathrm{kg} /$ day $)$ of caffeine per day. Similarly, Sabol et al. [37] found an improvement in medicine ball throw distance in a study conducted on habituated to caffeine participants $(358 \pm 210 \mathrm{mg} /$ day; $\sim 4.1 \mathrm{mg} / \mathrm{kg} /$ day) after ingestion of $6 \mathrm{mg} / \mathrm{kg}$ of caffeine. However, in the study of Sabol et al. [37], lower caffeine doses ( 2 and $4 \mathrm{mg} / \mathrm{kg}$ of caffeine) did not increase performance, which may suggest a reduction in ergogenic effects of caffeine in subjects with higher daily caffeine consumption. Interestingly, previous studies $[14,27,36]$ conducted on participants with daily caffeine intakes similar to those in the presented research (range from 4.2 to $5.1 \mathrm{mg} / \mathrm{kg} /$ day) did not show a positive effect of 3 and $6 \mathrm{mg} / \mathrm{kg}$ of caffeine (doses similar to a daily level of caffeine consumption) [14], or only partial improvement of strength-power performance were observed [27,36]. A summary of all these data suggests that in athletes with low habituation to caffeine (2-to- $4 \mathrm{mg} / \mathrm{kg} /$ day), the ingestion of an acute dose of 3 and $6 \mathrm{mg} / \mathrm{kg}$ of caffeine may exert ergogenic benefits in resistance and power-based exercise. However, in athletes with moderate-to-high habituation to caffeine (4-to- $6 \mathrm{mg} / \mathrm{kg} /$ day), doses of $9 \mathrm{mg} / \mathrm{kg}$ may be needed to obtain such ergogenic benefits on resistance-based exercise.

It should be noted that consumption of high doses of caffeine $(\geq 9 \mathrm{mg} / \mathrm{kg})$, although ergogenic for athletes habituated to chronic intake of caffeine, present higher prevalence of caffeine-associated side effects [22]. In the present study, the intake of $12 \mathrm{mg} / \mathrm{kg}$ of caffeine increased the prevalence of tachycardia/palpitations events, anxiety and activeness, headache, and gastrointestinal discomforts just after the end of the exercise protocol, while most of these drawbacks were still persistent $24 \mathrm{~h}$ after testing (Table 4). Interestingly, the current research showed that the prevalence of these side effect was dose-dependent, as $9 \mathrm{mg} / \mathrm{kg}$ produced slightly higher, and in most cases non-statistically significant prevalence of side effects when compared to the placebo. The relatively low frequency of side effects observed in the trial with $9 \mathrm{mg} / \mathrm{kg}$ of caffeine can be attributed to the fact that habitual caffeine users may develop tolerance to certain physiological effects of caffeine [21]. It should be noted that participants involved in the presented study had significantly higher daily caffeine intake than those from previous studies [16-19], which may have promoted the low prevalence of side effects with $9 \mathrm{mg} / \mathrm{kg}$. Thus, the reported level of side effects can be attributed to the fact that with repeated and regular intake of caffeine, the dose needed to induce caffeine's physiological effects increases [21]. The results of the presented study suggest that for moderate-to-high caffeine users, $9 \mathrm{mg} / \mathrm{kg}$ may be relatively safe, taking into account that dose produced a high prevalence of side effects in low consumers of caffeine [16]. However, despite expected performance improvements, the recommendation of such doses of caffeine has to be individualized as there is the possible occurrence of side effects that may negatively impact resistance exercise performance (e.g., in case of gastrointestinal problems) and recovery (e.g., in case of insomnia) [22].

In addition to its strengths, the present study has several limitations which should be addressed. (1) The study did not include any biochemical analysis, such as plasma/urinary caffeine concentrations which could help explain the direct causes of performance changes. (2) There was no analysis of genetic intolerance to caffeine in the tested participants. (3) We assed only several side effects $24 \mathrm{~h}$ after caffeine ingestion and the exercise protocol and thus long-term effects are unknown. This is important as evidence suggests that the prevalence of side effects increases with chronic intake, even with lower doses [39]. (4) During trials with caffeine, most participants reported that they had ingested caffeine. However, this might be associated with using higher doses of caffeine than used in previous studies, where a similar blinding protocol masked caffeine use in trials with lower doses [37,38]. (5) We analyzed only the effects of caffeine intake in moderate to high caffeine consumers; therefore, generalizing these results to a population with other levels of caffeine consumption would not be correct. 
The extrapolation of these conclusions to individuals with lower habitual caffeine intake, and for long-term use, should not be done because it may produce higher prevalence of side effects that may affect athletes' performance and well-being.

\section{Conclusions}

The intake of either 9 and $12 \mathrm{mg} / \mathrm{kg}$ of caffeine $60 \mathrm{~min}$ before a session with several sets of BPT exercise increased mean and peak bar velocity in athletes with moderate-to-high habitual caffeine intake. Both doses of caffeine produced a similar performance benefit but the ingestion of $12 \mathrm{mg} / \mathrm{kg}$ of caffeine significantly increased the frequency of negative side effects immediately after, and for the $24 \mathrm{~h}$ after testing. Thus, the ingestion of $9 \mathrm{mg} / \mathrm{kg}$ of caffeine prior to ballistic exercise can be considered an effective and safe supplementation protocol for individuals habituated to caffeine.

Author Contributions: Conceptualization: A.F.-S., M.K. methodology: A.F.-S., M.K.; formal analysis and investigation: M.K., A.F.-S. writing-original draft preparation: A.F.-S.; writing-review and editing: A.F.-S., M.W., M.K., J.D.C.; supervision: M.W., J.D.C. All authors have read and agreed to the published version of the manuscript.

Funding: The study was supported and funded by the statutory research of the Jerzy Kukuczka Academy of Physical Education in Katowice, Poland.

Institutional Review Board Statement: The study protocol was approved by the Bioethics Committee for Scientific Research, at the Academy of Physical Education in Katowice, Poland (3/2019), and performed according to the ethical standards of the Declaration of Helsinki, 2013.

Informed Consent Statement: Informed consent was obtained from all subjects involved in the study.

Data Availability Statement: The datasets used and/or analyzed during the current study are available from the corresponding author on reasonable request.

Acknowledgments: This study would not have been possible without our participants' commitment, time and effort.

Conflicts of Interest: The authors declare that they have no conflict of interest.

\section{References}

1. Grgic, J.; Grgic, I.; Pickering, C.; Schoenfeld, B.J.; Bishop, D.J.; Pedisic, Z. Wake up and Smell the Coffee: Caffeine Supplementation and Exercise Performance-an Umbrella Review of 21 Published Meta-Analyses. Br. J. Sports Med. 2020, 54, 681-688. [CrossRef]

2. Grgic, J.; Mikulic, P.; Schoenfeld, B.J.; Bishop, D.J.; Pedisic, Z. The Influence of Caffeine Supplementation on Resistance Exercise: A Review. Sports Med. 2019, 49, 17-30. [CrossRef]

3. Grgic, J.; Trexler, E.T.; Lazinica, B.; Pedisic, Z. Effects of Caffeine Intake on Muscle Strength and Power: A Systematic Review and Meta-Analysis. J. Int. Soc. Sports Nutr. 2018, 15, 11. [CrossRef] [PubMed]

4. Raya-González, J.; Rendo-Urteaga, T.; Domínguez, R.; Castillo, D.; Rodríguez-Fernández, A.; Grgic, J. Acute Effects of Caffeine Supplementation on Movement Velocity in Resistance Exercise: A Systematic Review and Meta-Analysis. Sports Med. 2020, 50, 717-729. [CrossRef] [PubMed]

5. Fredholm, B.; Bättig, K.; Holmén, J.; Nehlig, A.; Zvartau, E. Actions of Caffeine in the Brain with Special Reference to Factors That Contribute to Its Widespread Use. Pharmacol. Rev. 1999, 51, 83-133. [PubMed]

6. Tallis, J.; Duncan, M.J.; James, R.S. What Can Isolated Skeletal Muscle Experiments Tell Us about the Effects of Caffeine on Exercise Performance?: Effects of Caffeine on Skeletal Muscle Contractility. Br. J. Pharmacol. 2015, 172, 3703-3713. [CrossRef] [PubMed]

7. Tallis, J.; James, R.S.; Cox, V.M.; Duncan, M.J. The Effect of a Physiological Concentration of Caffeine on the Endurance of Maximally and Submaximally Stimulated Mouse Soleus Muscle. J. Physiol. Sci. JPS 2013, 63, 125-132. [CrossRef]

8. Del Coso, J.; Muñoz, G.; Muñoz-Guerra, J. Prevalence of Caffeine Use in Elite Athletes Following Its Removal from the World Anti-Doping Agency List of Banned Substances. Appl. Physiol. Nutr. Metab. 2011, 36, 555-561. [CrossRef] [PubMed]

9. Aguilar-Navarro, M.; Muñoz, G.; Salinero, J.; Muñoz-Guerra, J.; Fernández-Álvarez, M.; Plata, M.; Del Coso, J. Urine Caffeine Concentration in Doping Control Samples from 2004 to 2015. Nutrients 2019, 11, 286. [CrossRef]

10. Lara, B.; Ruiz-Moreno, C.; Salinero, J.J.; Del Coso, J. Time Course of Tolerance to the Performance Benefits of Caffeine. PLoS ONE 2019, 14, e0210275. [CrossRef]

11. Beaumont, R.; Cordery, P.; Funnell, M.; Mears, S.; James, L.; Watson, P. Chronic Ingestion of a Low Dose of Caffeine Induces Tolerance to the Performance Benefits of Caffeine. J. Sports Sci. 2017, 35, 1920-1927. [CrossRef]

12. Fredholm, B.B. Adenosine Receptors as Drug Targets. Exp. Cell Res. 2010, 316, 1284-1288. [CrossRef] 
13. Filip-Stachnik, A.; Wilk, M.; Krzysztofik, M.; Lulińska, E.; Tufano, J.J.; Zajac, A.; Stastny, P.; Del Coso, J. The Effects of Different Doses of Caffeine on Maximal Strength and Strength-Endurance in Women Habituated to Caffeine. J. Int. Soc. Sports Nutr. 2021, 18, 25. [CrossRef]

14. Wilk, M.; Filip, A.; Krzysztofik, M.; Maszczyk, A.; Zajac, A. The Acute Effect of Various Doses of Caffeine on Power Output and Velocity during the Bench Press Exercise among Athletes Habitually Using Caffeine. Nutrients 2019, 11, 1465. [CrossRef]

15. Wilk, M.; Krzysztofik, M.; Filip, A.; Zajac, A.; Del Coso, J. The Effects of High Doses of Caffeine on Maximal Strength and Muscular Endurance in Athletes Habituated to Caffeine. Nutrients 2019, 11, 1912, Errutum in 2019, 11, 2660. [CrossRef]

16. Pallarés, J.G.; Fernández-Elías, V.E.; Ortega, J.F.; Muñoz, G.; Muñoz-Guerra, J.; Mora-Rodríguez, R. Neuromuscular Responses to Incremental Caffeine Doses: Performance and Side Effects. Med. Sci. Sports Exerc. 2013, 45, 2184-2192. [CrossRef] [PubMed]

17. Pasman, W.; van Baak, M.; Jeukendrup, A.; de Haan, A. The Effect of Different Dosages of Caffeine on Endurance Performance Time. Int. J. Sports Med. 1995, 16, 225-230. [CrossRef]

18. Negaresh, R.; Del Coso, J.; Mokhtarzade, M.; Lima-Silva, A.E.; Baker, J.S.; Willems, M.E.T.; Talebvand, S.; Khodadoost, M.; Farhani, F. Effects of Different Dosages of Caffeine Administration on Wrestling Performance during a Simulated Tournament. Eur. J. Sport Sci. 2019, 19, 499-507. [CrossRef]

19. Flinn, S.; Gregory, J.; Mc Naughton, L.; Tristram, S.; Davies, P. Caffeine Ingestion Prior to Incremental Cycling to Exhaustion in Recreational Cyclists. Int. J. Sports Med. 1990, 11, 188-193. [CrossRef] [PubMed]

20. French, C.; McNaughton, L.; Davies, P.; Tristram, S. Caffeine Ingestion during Exercise to Exhaustion in Elite Distance Runners. Revision. J. Sports Med. Phys. Fitness 1991, 31, 425-432. [PubMed]

21. Turnbull, D.; Rodricks, J.V.; Mariano, G.F. Neurobehavioral Hazard Identification and Characterization for Caffeine. Regul. Toxicol. Pharmacol. 2016, 74, 81-92. [CrossRef]

22. Pickering, C.; Kiely, J. What Should We Do About Habitual Caffeine Use in Athletes? Sports Med. 2019, 49, 833-842. [CrossRef]

23. Van Soeren, M.H.; Graham, T.E. Effect of Caffeine on Metabolism, Exercise Endurance, and Catecholamine Responses after Withdrawal. J. Appl. Physiol. 1998, 85, 1493-1501. [CrossRef] [PubMed]

24. Fisher, S.; McMurray, R.; Berry, M.; Mar, M.; Forsythe, W. Influence of Caffeine on Exercise Performance in Habitual Caffeine Users. Int. J. Sports Med. 1986, 7, 276-280. [CrossRef] [PubMed]

25. Bangsbo, J.; Jacobsen, K.; Nordberg, N.; Christensen, N.J.; Graham, T. Acute and Habitual Caffeine Ingestion and Metabolic Responses to Steady-State Exercise. J. Appl. Physiol. 1992, 72, 1297-1303. [CrossRef] [PubMed]

26. Van Thuyne, W.; Roels, K.; Delbeke, F.T. Distribution of Caffeine Levels in Urine in Different Sports in Relation to Doping Control. Int. J. Sports Med. 2005, 26, 714-718. [CrossRef] [PubMed]

27. Wilk, M.; Filip, A.; Krzysztofik, M.; Gepfert, M.; Zajac, A.; Del Coso, J. Acute Caffeine Intake Enhances Mean Power Output and Bar Velocity during the Bench Press Throw in Athletes Habituated to Caffeine. Nutrients 2020, 12, 406. [CrossRef] [PubMed]

28. Graham, T.E. Caffeine and Exercise: Metabolism, Endurance and Performance. Sports Med. 2001, 31, 785-807. [CrossRef]

29. Filip, A.; Wilk, M.; Krzysztofik, M.; Del Coso, J. Inconsistency in the Ergogenic Effect of Caffeine in Athletes Who Regularly Consume Caffeine: Is It Due to the Disparity in the Criteria That Defines Habitual Caffeine Intake? Nutrients 2020, $12,1087$. [CrossRef]

30. Bühler, E.; Lachenmeier, D.W.; Winkler, G. Development of a Tool to Assess Caffeine Intake among Teenagers and Young Adults. Ernahr. Umsch. 2014, 58-63. [CrossRef]

31. Kim, T.-W.; Shin, Y.-O.; Lee, J.-B.; Min, Y.-K.; Yang, H.-M. Caffeine Increases Sweating Sensitivity via Changes in Sudomotor Activity During Physical Loading. J. Med. Food 2011, 14, 1448-1455. [CrossRef]

32. Cohen, J. Statistical Power Analysis for the Behavioral Sciences; Elsevier: Burlington, NJ, USA, 2013; ISBN 9781483276489.

33. Mora-Rodríguez, R.; Pallarés, J.G.; López-Gullón, J.M.; López-Samanes, Á.; Fernández-Elías, V.E.; Ortega, J.F. Improvements on Neuromuscular Performance with Caffeine Ingestion Depend on the Time-of-Day. J. Sci. Med. Sport 2015, 18, 338-342. [CrossRef]

34. Del Coso, J.; Salinero, J.J.; González-Millán, C.; Abián-Vicén, J.; Pérez-González, B. Dose Response Effects of a Caffeine-Containing Energy Drink on Muscle Performance: A Repeated Measures Design. J. Int. Soc. Sports Nutr. 2012, 9, 21. [CrossRef]

35. Giráldez-Costas, V.; Ruíz-Moreno, C.; González-García, J.; Lara, B.; Del Coso, J.; Salinero, J.J. Pre-Exercise Caffeine Intake Enhances Bench Press Strength Training Adaptations. Front. Nutr. 2021, 8, 622564. [CrossRef]

36. Filip-Stachnik, A.; Krzysztofik, M.; Kaszuba, M.; Leźnicka, K.; Kostrzewa, M.; Del Coso, J.; Wilk, M. Effects of Acute Caffeine Intake on Power Output and Movement Velocity During a Multiple-Set Bench Press Exercise Among Mild Caffeine Users. J. Hum. Kinet. 2021, 78, 219-228. [CrossRef] [PubMed]

37. Sabol, F.; Grgic, J.; Mikulic, P. The Effects of 3 Different Doses of Caffeine on Jumping and Throwing Performance: A Randomized, Double-Blind, Crossover Study. Int. J. Sports Physiol. Perform. 2019, 14, 1170-1177. [CrossRef]

38. Grgic, J.; Mikulic, P. Acute Effects of Caffeine Supplementation on Resistance Exercise, Jumping, and Wingate Performance: No Influence of Habitual Caffeine Intake. Eur. J. Sport Sci. 2020, 1-11. [CrossRef] [PubMed]

39. Ruiz-Moreno, C.; Lara, B.; Gutiérrez-Hellín, J.; González-García, J.; Del Coso, J. Time Course and Magnitude of Tolerance to the Ergogenic Effect of Caffeine on the Second Ventilatory Threshold. Life 2020, 10, 343. [CrossRef] [PubMed] 